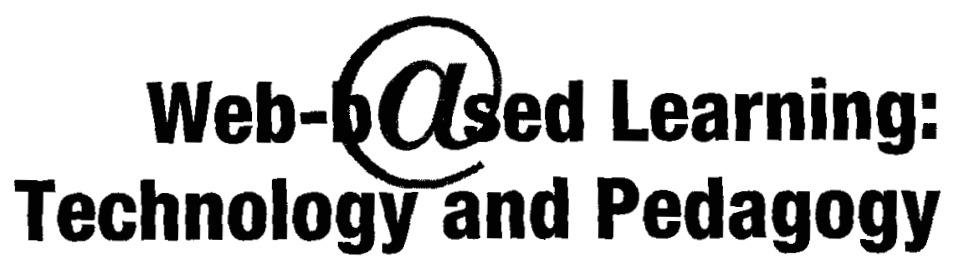


This page intentionally left blank 
editors

\section{Reggie Kwan}

Open University of Hong Kong

Joseph Fong

City University of Hong Kong

Proceedings of the 4th International Conference

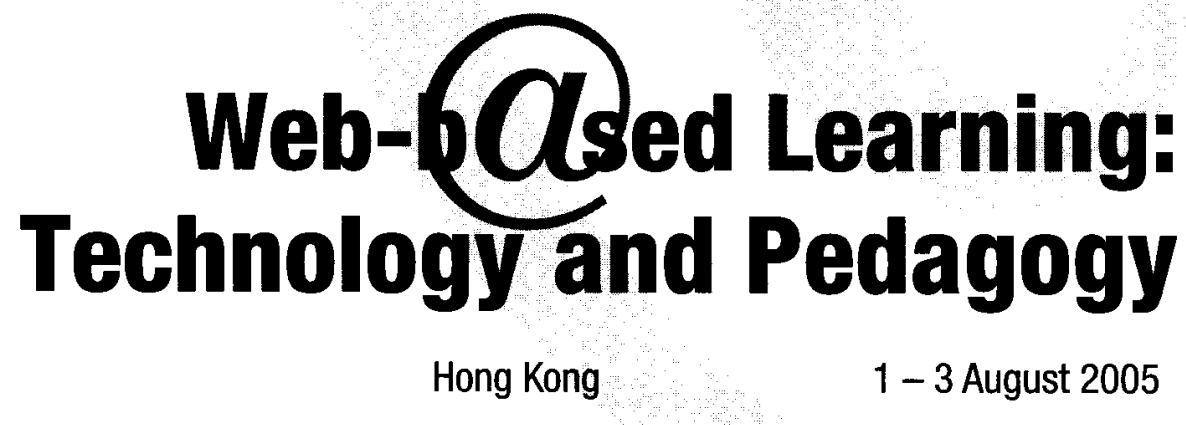




\section{Published by}

World Scientific Publishing Co. Pte. Ltd.

5 Toh Tuck Link, Singapore 596224

USA office: 27 Warren Street, Suite 401-402, Hackensack, NJ 07601

UK office: 57 Shelton Street, Covent Garden, London WC2H 9HE

\section{British Library Cataloguing-in-Publication Data}

A catalogue record for this book is available from the British Library.

\section{WEB-BASED LEARNING \\ Technology and Pedagogy \\ Proceedings of the 4th International Conference}

Copyright $\odot 2005$ by World Scientific Publishing Co. Pte. Ltd.

All rights reserved. This book, or parts thereof, may not be reproduced in any form or by any means, electronic or mechanical, including photocopying, recording or any information storage and retrieval system now known or to be invented, without written permission from the Publisher.

For photocopying of material in this volume, please pay a copying fee through the Copyright Clearance Center, Inc., 222 Rosewood Drive, Danvers, MA 01923, USA. In this case permission to photocopy is not required from the publisher.

ISBN 981-256-430-6 (pbk)

Printed in Singapore by Mainland Press 

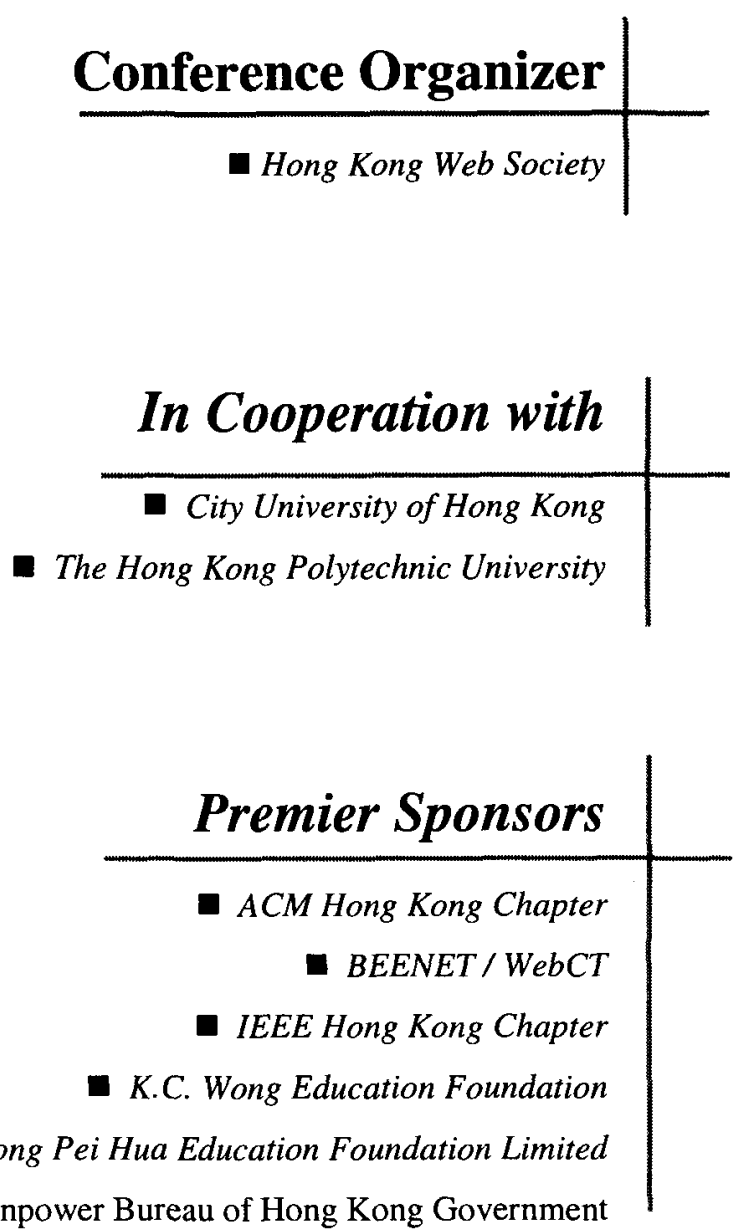

- Education and Manpower Bureau of Hong Kong Government

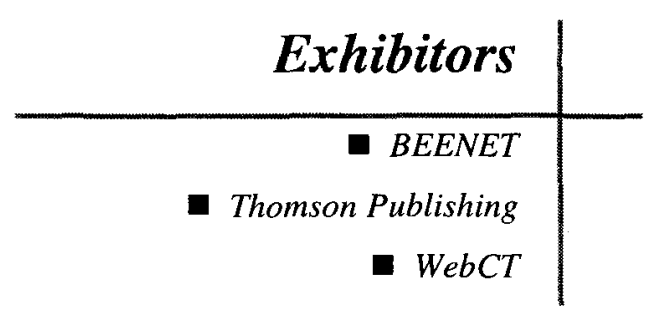


This page intentionally left blank 


\section{Foreword}

Hong Kong Web Society has been organizing an annual international conference on Web-based Learning since 2001. The conference has attracted many academic scholars and industrial practitioners to submit papers and share discussions during their papers presentation in the conference. Overall, more than 100 papers are reviewed by the conference program committee in each conference. These papers cover the advancement technology of infrastructure as well as the learning behavior and the teaching effectiveness of eLearning. Basically, we can summarize them into four areas as follows:

eLearning for adaptive learning -

In order to speed up the learning curve of learners, we aim to supplement cLearning (class room learning) with eLearning (online learning through Internet). The students can do self learning from web-based learning exercises on the Internet, which will assess the students academic level and provide them with suitable online exercises to work on. As a result, the students can learn everywhere and any time through Internet.

eLearning for teacher helpers -

In order to reduce teachers' work load on authoring exercises for their students, on getting students feedbacks and on communicate with students more effectively, many eLearning systems facilitate these functionalities to the teachers as their helpers. For example, eLearning authoring tool can help teachers to prepare exercises, and blog journal file can help teachers getting students feedback on a particular learning problem or subject.

eLearning for distance learning -

Besides traditional class room learning, students can also access learning facilities remotely. For example, a virtual cyber laboratory can help students to perform their laboratory exercises at home through Internet. An online tutorial session can help students access to their tutors through their notebook computers. As a result, students can learn in a very comfortably environment without traveling time, cost and hassle.

eLearning technology infrastructure -

In order to make eLearning a success, technology infrastructure is a must. In fact, eLearning is more cost effective whenever it can be accessed by mass learners 
viii

because individual cost will be less with increased number of learners for eLearning while the eLearning development time and effort is fixed. In other words, once an eLearning package has been on production, it can be reused for many times with minimum operation cost. However, such mass learners operations need the support of technology. As a result, research on eLearning technology infrastructure is another important area for researchers to explore.

Finally, we appreciate the authors who have submitted so many papers to this conference and make it a success in the world of eLearning.

Joseph Fong Co-chair of the ICWL 2005 Applied Track 


\section{ICWL 2005 Conference Committee}

Honorary Co-Chairs

Conference Co-Chairs

Program Co-Chairs

Organization Co-Chairs

Communications Coordinator

Treasurer

Publication Co-Chairs

Media Chair

Application Co-Chairs

Tutorial Chair

Publicity Co-Chairs

Local Arrangements
Keith Chan, The Hong Kong Polytechnic University

Frances Yao, City University of Hong Kong

Kamal Karlapalem, IIIT (India)

Qing Li, Hong Kong Web Society

Ronnie Cheung, The Hong Kong Polytechnic University

Rynson W. H. Lau, City University of

Hong Kong

Hong-Va Leong, The Hong Kong Polytechnic University

Marian Choy, City University of Hong Kong

Taku Komura, City University of Hong Kong

C. W. Ngo, City University of Hong Kong

Wenyin Liu, City University of Hong Kong Ming Cheung, City University of Hong Kong

Frederick Li, The Hong Kong Polytechnic University

Joseph Fong, City University of Hong Kong Reggie Kwan, The Open University of Hong Kong

Kenneth Lau, ICON Limited

Howard Leung, City University of Hong Kong

L. F. Kwok, City University of Hong Kong Qun Jin, Waseda University, Japan

Edward Ho, The Hong Kong Polytechnic University 
This page intentionally left blank 


\section{Welcome}

Welcome to Hong Kong and ICWL 2005. We are thrilled to have ICWL back in Hong Kong after ICWL 2003 in Melbourne and ICWL 2004 in Beijing. For the out-of-towners, we wish you have fun in Hong Kong.

Now, ICWL is in its fourth year. We are ecstatic to witness the advances of the field. In the past four years, different tools, models, and applications have been developed, deployed, and evaluated. We look forward to meeting with all of you to exchange ideas and to take web-based learning to new heights.

We would like to take this opportunity to thank every single author for contributing to the field of Web-based learning. We are also grateful for all reviewers for their effort in reviewing the many papers. We also owe it to all the colleagues who took care of the logistics and made this book and ICWL 2005 a success.

Finally, we would like to express our most heart-felt thanks to all the organizations that support this conference. We are grateful to the Hong Kong Web Society for hosting this conference; to BEENET and WebCT, Pui-Hua Education Foundation, K.C. Wong Foundation, City University of Hong Kong, the Polytechnic University of Hong Kong, and the Education and Manpower Bureau of Hong Kong Government for their sponsorship. 
This page intentionally left blank 


\title{
International Program Committee
}

\author{
Brian d'Auriol University of Texas, USA \\ Howard Beck University of Florida, USA \\ Stephane Bressan National University of Singapore, Singapore \\ Wentong Cai Nanyang Technological University, Singapore \\ Jiannong Cao The Hong Kong Polytechnic University, HK \\ Keith Chan The Hong Kong Polytechnic University, HK \\ Shi-Kuo Chang Chang University of Pittsburgh, USA \\ Arbee Chen National Tsing Hua University, Taiwan \\ Marian Choy City University of Hong Kong, HK \\ Jo Coldwell Deakin University, Australia \\ Tharam Dillon Sydney University of Technology, Australia \\ Guozhu Dong Wright State University, USA \\ Ling Feng University of Twente, Netherlands \\ Joseph Fong City University of Hong Kong, HK \\ Andrzej Goscinski Deakin University, Australia \\ Edward Ho \\ Runhe Huang \\ Weijia Jia \\ Qun Jin \\ Ryoichi Komiya \\ Taku Komura \\ Reggie Kwan \\ L. F. Kwok \\ Dik Lee \\ Sue Legg \\ H.V. Leong \\ Clement Leung \\ Howard Leung \\ Frederick Li \\ The Hong Kong Polytechnic University, HK \\ Hosei University, Japan \\ City University of Hong Kong, HK \\ Waseda University, Japan \\ Multimedia University, Malaysia \\ City University of Hong Kong, HK \\ The Open University of Hong Kong, HK \\ City University of Hong Kong, HK \\ HKUST, HK \\ University of Florida, USA \\ The Hong Kong Polytechnic University, HK \\ Victoria University of Technology, Australia \\ City University of Hong Kong, HK \\ The Hong Kong Polytechnic University, HK
}


Keqin Li

Minglu Li

Wenyin Liu

Xiaofeng Meng

John Murnane

C. W. Ngo

Zhiyong Peng

Geoff Romeo

Timothy Shih

Chengzheng Sun

Lily Sun

Boleslaw Szymanski

Changjie Tang

Guoren Wang

Limin Xiang

Simon Yip

Kang Zhang

S. Q. Zheng
State University of New York at New Paltz, USA

Shanghai Jiao Tong University, China

City University of Hong Kong, HK

Renming University, China

Melbourne University, Australia

City University of Hong Kong, HK

Wuhan University, China

Monash University, Australia

Tamkang University, Taiwan

Griffith University, Australia

The University of Reading, UK

Rensselaer Polytechnic Institute, USA

Sichuan University, China

Northeastern University, China

Kyusan University, Japan

The Chinese University of Hong Kong, HK

University of Texas at Dallas, USA

University of Texas at Dallas, USA 


\section{Contents}

Foreword vii

ICWL 2005 Conference Committee ix

Welcome xi

International Program Committee xiii

\section{PART ONE Tools}

1. The InterTEST Web-Based Multiple-Choice Testing Software: Developing and Evaluating On-Line English Language Tests

Philippos Pouyioutas, Victoria Kalogerou, and Maria Poveda

2. WebLec: A Full-Scale Lesson Management Support System Developed by University Students

Satoshi Uchida

3. On or Off the Slate: University Library E-Reserve Supports

Web-based Learning

Ophelia Cheung

4. Design and Implement of The Web-based Virtual Laboratory for On-Campuse Circuit Courses

Gu Rong, Zhu Miaoliang, and Dong Yabo

5. A Mechanism for Knowledge Map Construction on Personalized E-Learning Platform: A Semantic Approach

S. M. Huang, H. Y. Hsueh, and H. Y. Jiang

6. Yet Another Platform for Web-based Learning

T. S. Li, S. M.Wong, and Reggie Kwan 
xvi

\section{PART TWO Models}

7. Blended Learning Approach: A Strategy to Address the Issue of Declining Enrollment in Mechanical Programs and A Promising Model in Teaching AutoCAD in Arabic

R. Bedri and M. O. Al-Nais

8. Concept Maps and Learning Objects

Leonel Iriarte Navarr, Manuel Marco Such, Pedro Pernias Peco, and Daniel Moron Martin

9. The Construction of Web-based Mastery Learning System

Hsien Tang Lin, Zhi Feng Liu, and Shyan-Ming Yuan

10. Enhancing Problem-based Learning by E-learning: A Study with the Teaching of Data Structures and Algorithms

Kent K. T. Cheung, Alan Y. K. Chan, and Paul K. O. Chow

11. How Should Online Tutors be Trained?

A Four-level of Evaluation for E-moderating Programme

Eva Tsang

12. Methodology for Developing Dynamic Web Authoring System for E-Learning

Yin Fei Yeung and Joseph Fong

\section{PART THREE Applications}

13. Creation of a Library of Learning Objects (LO) from Pre Existing Contents

Leonel Iriarte Navarr, Manuel Marco Such, Pedro Pernias Peco, and Daniel Moron Martin

14. A Mobile Agent Assisted Learning Resource Service Framework based on SOAP

Wu Di, Yang Zongkai, and Cheng Wenqing

15. Teaching Stroke Order of Chinese Characters by Using Minimal Feedback 
16. An On-Line Programming Environment with Automated Assessment 145 Ronnie Cheung

17. Webits and Quality Control in Marking of Examination Scripts Philip Tsang, Reggie Kwan, Andrew K. Lui, and Henry Lo

\section{PART FOUR Human Factors}

18. Social Capital Creation and Reciprocity in Online Learning Platforms

Andrew K. Lui, Yannie Cheung, and Reggie Kwan

19. Are Teachers in Hong Kong Ready for e-Learning?

Teddy Koon Keung So

20. Implementation Issues on the Specification for Service Quality Management of e-Learning

Yi Zhang, Zhiting Zhu, Chengling Zhao, Zongkai Yang, and Sanlan Lu

21. A Comparative Evaluation and Correlation Between Learning Styles and Academic Achievement on E-Learning Daniel Su

22. A web-based environment for better administration of distance learning courses

S. C. Ng, S. O. Choy, R. Kwan, and Y. C. Tsang 